ORIGINAL ARTICLE

\title{
Effects of inhaled bronchodilators and corticosteroids on exercise induced arterial hypoxaemia in trained male athletes
}

\author{
A N H Hodges, B M Lynn, M S Koehle, D C McKenzie
}

Br J Sports Med 2005;39:917-920. doi: 10.1136/bjsm.2005.017806

\begin{abstract}
See end of article for authors' affiliations

.....................

Correspondence to: A N H Hodges, School of Human Kinetics, University of British Columbia, Vancouver, V6T 2G9 Canada; alastairhodges@ hotmail.com
\end{abstract}

Accepted 23 May 2005

\begin{abstract}
Objectives: To determine the effect of prophylactic treatment with an inhaled bronchodilator and antiinflammatory on arterial saturation $\left(\mathrm{SaO}_{2}\right)$ in trained non-asthmatic male athletes with exercise induced arterial hypoxaemia (EIAH).

Methods: Nine male athletes (mean (SD) age $26.3(6.7)$ years, height $182.6(7.9) \mathrm{cm}$, weight 79.3 (10.5) kg, VO 2 MAX $62.3(6.3) \mathrm{ml} / \mathrm{kg} / \mathrm{min}, \mathrm{SaO}_{2} \mathrm{MIN} 92.5(1.1) \%$ ) with no history of asthma were tested in two experimental conditions. A combination of a therapeutic dose of salbutamol and fluticasone or an inert placebo was administered in a randomised crossover design for seven days before maximal cycling exercise. Oxygen consumption $\left(\mathrm{VO}_{2}\right)$, ventilation $(\mathrm{VE})$, heart rate $(\mathrm{HR})$, power output, and $\mathrm{SaO}_{2}$ were monitored during the exercise tests.

Results: There were no significant differences between the drug (D) and placebo (P) conditions for minimal $\mathrm{SaO}_{2}(\mathrm{D}=93.6(1.4), \mathrm{P}=93.0(1.1) \% ; \mathrm{p}=0.93) \mathrm{VO}_{2} \mathrm{MAX}(\mathrm{D}=61.5(7.2), \mathrm{P}=61.9(6.3) \mathrm{ml} / \mathrm{kg} / \mathrm{min}$; $p=0.91)$, peak power $(D=444.4(48.3), P=449.4(43.9) W ; p=0.90)$, peak $V E(D=147.8(19.1)$, $P=149.2(15.5)$ litres $/ \mathrm{min} ; P=0.82)$, or peak heart rate $(D=182.3(10.0), P=180.8(5.5)$ beats/ $\min ; \mathrm{p}=0.76)$.

Conclusions: A therapeutic dose of salbutamol and fluticasone did not attenuate EIAH during maximal cycling in a group of trained male non-asthmatic athletes.
\end{abstract}

$\mathrm{H}$ istorically, 50\% of highly trained male athletes ${ }^{1}$ and a greater number of female athletes ${ }^{2}$ develop exercise induced arterial hypoxaemia (EIAH) during maximal exercise. These athletes, unable to maintain arterial oxygen saturation $\left(\mathrm{SaO}_{2}\right)$, show decreases in indicators of endurance performance $^{3}$ and a reduced maximal aerobic capacity. ${ }^{4}$ These observations have fuelled research over the last two decades to investigate the possible mechanisms, which include intrapulmonary shunting of blood, relative alveolar hypoventilation, ventilation perfusion inequality, and pulmonary diffusion limitations. ${ }^{5}$ These mechanisms have attracted a great deal of attention but the underlying causes of EIAH have yet to be completely understood. ${ }^{5}$ It has been documented that athletes unable to maintain $\mathrm{SaO}_{2}$ show hindered physical performance in terms of decreased maximal aerobic capacity ${ }^{4}$ and physical working capacity. ${ }^{3}$

In this study, the response to asthma inhaler medication was examined in normal subjects assumed to be nonasthmatic. Subjects with asthma have increased inflammation of the lung, and compromised ventilation secondary to bronchoconstriction is common. The standard of care for these patients is the administration of inhaled corticosteroids and bronchodilators. These drugs are effective in reversing airway obstruction and reducing lung inflammation, which allows asthmatics to perform sport and physical activity similar to normal, healthy people.

Strenuous exercise, in asthmatic and non-asthmatic athletes, initiates an acute inflammatory response with leucocytosis, neutrophil activation, and release of inflammatory mediators and acute phase proteins. ${ }^{6}$ Mediators of airway or vascular tone can also alter ventilation and/or perfusion distributions, and this observation is supported by increased histamine concentrations in athletes with EIAH, and improvement in impaired gas exchange with the administration of nedocromil sodium. ${ }^{8}$
Anti-inflammatory drugs have been administered immediately before exercise, and the effects on EIAH observed. ${ }^{8-10}$ To our knowledge, a combination of bronchodilators and corticosteroid drugs, used daily to suppress lung inflammation and reverse bronchoconstriction, has not been used to attenuate EIAH in athletes who experience this condition. Fluticasone is a corticosteroid that inhibits production of inflammatory cells (mast cells, basophils, lymphocytes) and cytokines. Salbutamol is a selective short acting $\beta_{2}$ adrenergic agonist that acts as a bronchodilator. The purpose of this study therefore was to examine the effect of a seven day therapeutic administration of fluticasone and salbutamol on the $\mathrm{SaO}_{2}$ of subjects with demonstrated EIAH.

\section{METHODS}

\section{Subjects}

Written informed consent was obtained from all subjects before participation. No subject was taking any drugs, and none presented symptoms of any infection during the study. The University of British Columbia Committee on Human Experimentation approved this study.

\section{Experimental design}

A randomised, double blinded, crossover design was used. Subjects reported to the laboratory on four separate occasions separated by at least 72 hours. On the first screening visit, anthropometric measures were recorded and an incremental maximal cycle to exhaustion test (maximum oxygen consumption $\left(\mathrm{VO}_{2} \mathrm{MAX}\right)$ test) was performed. The second visit was also used for screening purposes and was identical with

Abbreviations: $\mathrm{EIAH}$, exercise induced arterial hypoxaemia; $\mathrm{FEV}_{1}$, forced expiratory volume in one second; FVC, forced vital capacity; $\mathrm{SaO}_{2}$, arterial oxygen saturation; $\mathrm{VO}_{2} \mathrm{MAX}$, maximum oxygen consumption 
Table 1 Maximal exercise data

\begin{tabular}{lll}
\hline Variable & Placebo & Drug \\
\hline $\mathrm{SaO}_{2}(\%)$ & $93.0(1.1)$ & $93.6(1.4)$ \\
$\mathrm{VO}_{2} \mathrm{MAX}(\mathrm{ml} / \mathrm{kg} / \mathrm{min})$ & $61.9(6.3)$ & $61.5(7.2)$ \\
$\mathrm{Power} \mathrm{W})$ & $449.4(43.9)$ & $444.4(48.3)$ \\
$\mathrm{VE}($ litres $/ \mathrm{min})$ & $149.2(15.5)$ & $147.8(19.1)$ \\
$\mathrm{HRmax}$ (beats/min) & $180.8(5.5)$ & $182.3(10.0)$ \\
\hline
\end{tabular}

Values are means (SD) ( $\mathrm{n}=9$ ).

$\mathrm{SaO}_{2}$, arterial oxygen saturation; $\mathrm{VO}_{2} \mathrm{MAX}$, maximum oxygen consumption; HRmax, maximum heart rate. the first. For inclusion in the study, subjects were required to show a $\mathrm{VO}_{2} \mathrm{MAX}$ of greater than $60 \mathrm{ml} / \mathrm{kg} / \mathrm{min}$ and a minimum $4 \%$ fall in $\mathrm{SaO}_{2}$ from resting values during the $\mathrm{VO}_{2} \mathrm{MAX}$ tests on each of the first two visits. The purpose of the second identical $\mathrm{VO}_{2} \mathrm{MAX}$ test was to show reproducible EIAH. On the third and fourth sessions, subjects completed a $\mathrm{VO}_{2} \mathrm{MAX}$ test after seven days of the drug (D) or placebo (P) condition in a randomised order. There was a minimum of seven days washout period between the placebo and drug conditions.

To ensure that all of the subjects had normal resting pulmonary function, flow volume loops and forced expiratory volume in one second $\left(\mathrm{FEV}_{1}\right)$ (Medical Graphics Cardiopulmonary Exercise System CPX/D, St Paul, Minnesota, USA) were performed on the first visit to the laboratory. Calibration was performed before each session. Subjects performed three trials, and the highest $\mathrm{FEV}_{1}$ was recorded. For inclusion in the study, an $\mathrm{FEV}_{\mathrm{l}} /$ forced vital capacity (FVC) greater than 0.8 was required. However, a more specific asthma test-for example, methacholine challenge or eucapnic hyperventilatory response test-was not performed.

\section{The maximal exercise test}

Subjects were requested not to perform any exhaustive exercise for 24 hours before each testing session. The graded exercise test was performed on an electronically braked cycle ergometer (Quinton Excalibur, Lode, Groningen, the Netherlands). Subjects started at $0 \mathrm{~W}$ and increased at a rate of $30 \mathrm{~W} / \mathrm{min}$ and were encouraged to maintain pedal speed above $90 \mathrm{rev} / \mathrm{min}$. The test stopped when they experienced volitional fatigue and could not maintain this pedalling rate for 15-20 seconds. All subjects achieved a respiratory quotient $>1.10$. Expired gases were collected and analysed (Ametek, Pittsburgh, Pennsylvania, USA), and ventilation was measured (Flo-1B; Physio-Dyne Fitness Instrument Technologies, Quogue, New York, USA) and averaged every 15 seconds. Heart rate was measured by telemetry (Polar Vantage XL, Kemple, Finland) and averaged every 15 seconds. $\mathrm{VO}_{2} \mathrm{MAX}$ was calculated as the average of the

\begin{tabular}{lccl} 
Table 2 & \multicolumn{3}{l}{ Individual spirometry data } \\
\hline Subject & FVC (litres) & FEV $_{\mathbf{l}}$ /FVC (\%) & FEF $_{25-75}$ (litres/s) \\
\hline 1 & 5.3 & 84.3 & 4.8 \\
2 & 7.3 & 80.9 & 4.5 \\
3 & 5.5 & 82.3 & 4.2 \\
4 & 5.9 & 80.7 & 5.7 \\
5 & 5.6 & 81.0 & 4.3 \\
6 & 5.4 & 86.2 & 4.8 \\
7 & 6.4 & 82.4 & 5.9 \\
8 & 4.4 & 80.2 & 4.7 \\
9 & 5.2 & 81.4 & 5.0 \\
Mean & 5.8 & 82.2 & 4.9 \\
SD & 0.8 & 2.0 & 0.6 \\
\hline FEV & Forced expiratory volume in one second; FVC, forced vital capacity; \\
FEF $_{25-75}$, forced expiratory flow from 25 to 75\%.
\end{tabular}

four highest consecutive readings. Peak power achieved at the end of the test was recorded. Arterial oxyhaemoglobin saturation was measured continuously by ear oximetry (Biox 3740; Ohmeda, Madison, Wisconsin, USA) and recorded every 15 seconds. The lowest $\mathrm{SaO}_{2}$ value was obtained during the last minute of the $\mathrm{VO}_{2} \mathrm{MAX}$ test. It is preferable to monitor EIAH through direct measurement of $\mathrm{PO}_{2}$ in arterial blood. However, we were limited in our ability to perform this measure on the population of subjects selected in this study. This should be noted as a limitation in the study methods that may lead to some inaccuracies in our assessment of EIAH in these subjects.

\section{Drug administration}

Twice daily, for seven days, subjects inhaled $400 \mu \mathrm{g}$ salbutamol and $500 \mu \mathrm{g}$ fluticasone from two separate inhalers or an identical placebo that had no active medication. The final administration of the two inhalers took place in the laboratory 15 minutes before the beginning of the exercise test. In the placebo condition, two inhalers were also used to maintain the integrity of the blinding. The order of administration of the two drugs was not controlled. An AeroChamber (Boehringer Ingelheim, Burlington, Ontario, Canada) spacer was used to maximise inhalation of the drugs. Detailed instruction and practice with the inhalers were given to each subject. The inhalers were randomly coded, enabling double blinding of the administration order.

\section{Data analysis}

Multiple analysis of variance was used to assess $\mathrm{SaO}_{2}$, $\mathrm{VO}_{2}$ MAX, peak power, ventilation $(\mathrm{VE})$, and heart rate data for each treatment condition. A repeated measures analysis of variance was used to examine $\mathrm{SaO}_{2}$ over time during the exercise test in each condition. For all analyses, $\alpha$ was set at 0.05 .

\section{RESULTS}

Nine healthy male subjects participated in this study (mean (SD) age 26.3 (6.7) years; $\mathrm{VO}_{2} \operatorname{MAX} 62.3$ (6.3) $\mathrm{ml} / \mathrm{kg} / \mathrm{min}$ ). Normal spirometry data were obtained on all nine subjects. Table 1 shows mean maximal exercise data for the nine subjects, and table 2 shows $\mathrm{FVC}, \mathrm{FEV}_{1}$, and forced expiratory flow from $25 \%$ to $75 \%$ for the individual subjects. No significant differences were found between the drug and placebo conditions for minimum $\mathrm{SaO}_{2}(\mathrm{p}=0.93), \mathrm{VO}_{2} \mathrm{MAX}(\mathrm{p}$ $=0.91)$, peak power $(p=0.90)$, peak $\operatorname{VE}(p=0.82)$, or maximal heart rate $(p=0.76)$ (table 1$)$. There was a significant decrease in $\mathrm{SaO}_{2}$ from rest at $50 \%, 75 \%$, and $100 \%$ $\mathrm{VO}_{2} \mathrm{MAX}$ for each treatment $(\mathrm{p}<0.05)$, but there were no

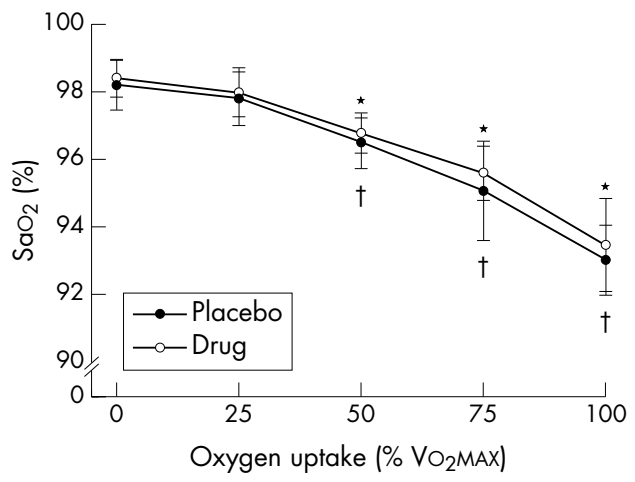

Figure 1 Arterial oxygen saturation $\left(\mathrm{SaO}_{2}\right)$ during incremental exercise. $\mathrm{VO}_{2} \mathrm{MAX}$, maximum oxygen consumption. ${ }^{*}$ Drug significantly lower than rest $(p<0.05)$. TPlacebo significantly lower than rest $(p<0.05)$ 


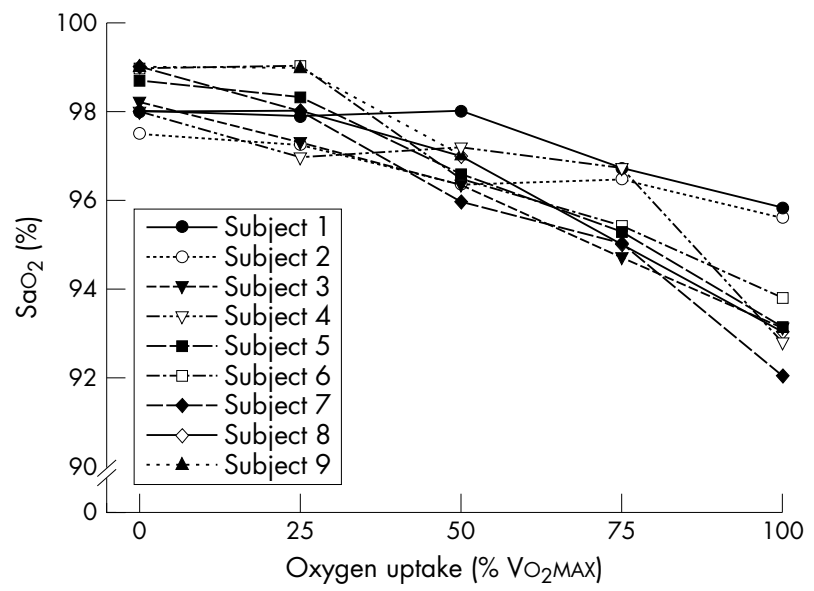

Figure 2 Drug condition: individual arterial oxygen saturation $\left(\mathrm{SaO}_{2}\right)$. $\mathrm{VO}_{2} \mathrm{MAX}$, maximum oxygen consumption.

significant differences in $\mathrm{SaO}_{2}$ between treatments at any workload (fig 1). Figures 2 and 3 show the individual $\mathrm{SaO}_{2}$ exercise data for the drug and placebo conditions respectively. All nine subjects showed a minimum fall of $4 \%$ in $\mathrm{SaO}_{2}$ in the first two $\mathrm{VO}_{2} \mathrm{MAX}$ tests.

\section{DISCUSSION}

Our results indicate that a seven day treatment with an inhaled bronchodilator and corticosteroid did not alter $\mathrm{SaO}_{2}$ during incremental cycling exercise to exhaustion in nonasthmatic trained male athletes with EIAH.

Airway inflammation occurs during exercise induced asthma and may limit exercise in asthmatics. ${ }^{11}$ We hypothesised that a similar response in healthy subjects may contribute to EIAH. Previously, drugs normally used in the control of the asthma inflammatory response in asthmatics have been used in an attempt to reduce the severity of arterial haemoglobin desaturation experienced by subjects with EIAH. Inhaled nedocromil sodium, a histamine release inhibitor, has been shown to improve pulmonary gas exchange in several classes of athletes including male master athletes (63.2 (1.9) years) and aerobically trained athletes. $^{81213}$ However, nedocromil sodium was found to have no effect on pulmonary gas exchange in aerobically fit men and women when administered in conjunction with

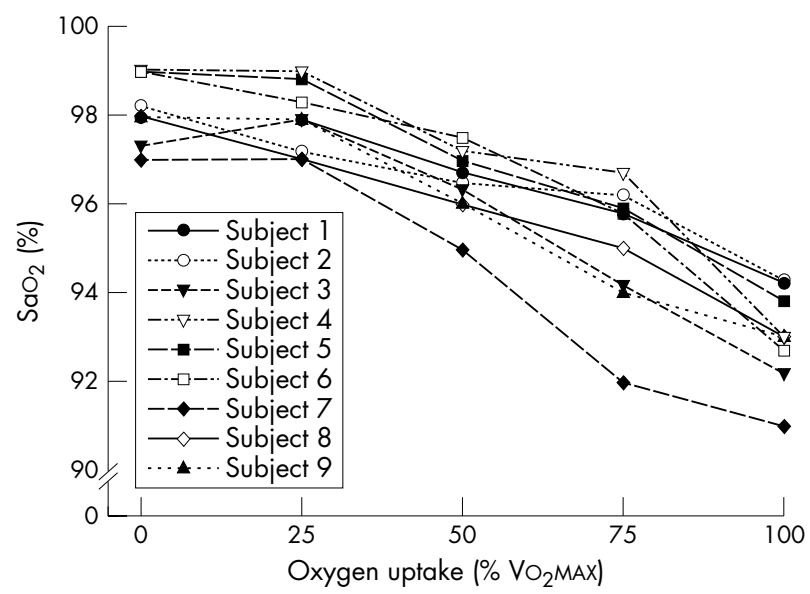

Figure 3 Placebo condition: individual arterial oxygen saturation $\left(\mathrm{SaO}_{2}\right)$. $\mathrm{VO}_{2} \mathrm{MAX}$, maximum oxygen consumption.
What is already known on this topic

It has been shown that an inhaled bronchodilator has no effect on exercise induced arterial hypoxaemia.

\section{What this study adds}

This study shows that a combination of inhaled corticosteroids and bronchodilators does not have any effect on exercise induced arterial hypoxaemia, strengthening the notion that this condition is not the result of lung airway inflammation.

fexofenadine hydrochloride (a peripheral $\mathrm{H}_{1}$ receptor antagonist) and zileuton (a leukotriene inhibitor). ${ }^{10} \mathrm{~A}$ recent study has examined the effects of a single dose of a long or short acting $\beta_{2}$ agonist (formoterol and salbutamol respectively) on trained non-asthmatic subjects during cycle ergometer exercise to exhaustion. ${ }^{9}$ No significant differences were found for any maximal exercise variables (workload, $\mathrm{VO}_{2}$, $\mathrm{VE}$, and $\mathrm{SaO}_{2}$ ) between the two drugs or the placebo condition. It appears then that, if an inflammatory response is the cause of EIAH in these subjects, either specific drugs but not others mediate this response, or clearly there are other mechanisms involved in the decrease in $\mathrm{SaO}_{2}$ during exercise.

It was our belief that a longer term control of lung inflammation may be useful in examination of the hypoxaemic response in these subjects. Previous studies involving the administration of drugs in subjects with EIAH have used a single dose immediately before exercise. This study was unique with the use of a corticosteroid inhaler for seven days. Any chronic lung inflammation would have been controlled through the effects of the prolonged use of a bronchodilator and corticosteroid.

It is worth noting that paradoxical bronchoconstriction and/or bronchospasm have been observed after administration of $\beta_{2}$ agonist drugs. ${ }^{14}$ It may be prudent in the study of the effect of such drugs on exercise to include spirometry measures before and after each administration of the drug. Regular spirometry measures were a limitation in this study because of the nature of the self administration of the drugs at home for seven days. Nevertheless, none of our subjects reported any symptoms of bronchoconstriction nor complained of any change in breathing ability after administration of the $\beta_{2}$ agonist.

A further limitation of this study was our decision to use the determination of $\mathrm{VO}_{2} \mathrm{MAX}$ as the exercise challenge. Although the advantage of this type of exercise is that EIAH is readily reproducible, it may have been prudent to have subjects maintain a high intensity of exercise for an extended period of time. In this type of study examining the role of airway inflammation on EIAH, it is possible that, during a prolonged exercise bout, subjects would show greater airway irritation and inflammation.

We found no difference in any exercise data after a seven day administration of inhaled bronchodilators and corticosteroids, and therefore we conclude that inhaled asthma drugs of this nature have no effect on EIAH.

\section{ACKNOWLEDGEMENTS}

We thank Diana Jespersen for her technical assistance with this study. 


\section{Authors' affiliations}

A N H Hodges, M S Koehle, D C McKenzie, School of Human Kinetics, University of British Columbia, Vancouver, Canada

B M Lynn, University of Oregon, Portland, Oregon, USA

Competing interests: none declared

\section{REFERENCES}

1 Dempsey JA, Hanson PG, Henderson KS. Exercise-induced arterial hypoxaemia in healthy human subjects at sea level. J Physiol (Lond) 1984;355: 161-75.

2 Harms CA, McClaran SR, Nickele GA, et al. Exercise-induced arterial hypoxaemia in healthy young women. J Physiol (Lond) 1998:507:619-28.

3 Koskolou MD, McKenzie DC. Arterial hypoxemia and performance during intense exercise. Eur J Appl Physiol 1994;68:80-6.

4 Powers SK, Lawler J, Dempsey JA, et al. Effects of incomplete pulmonary gas exchange on $\mathrm{vo}_{2}$ max. J Appl Physiol 1989;66:2491-5.

5 Dempsey JA, Wagner PD. Exercise-induced arterial hypoxemia. J Appl Physiol 1999;87:1997-2006.

6 Moyna NM, Acker GR, Fulton JR, et al. Lymphocyte function and cytokine production during incremental exercise in active and sedentary males and females. Int J Sports Med 1996;17:585-91.
7 Anselme F, Caillaud C, Couret I, et al. Histamine and exercise-induced hypoxemia in highly trained athletes. J Appl Physiol 1994;76:127-32.

8 Prefaut C, Anselme-Poujol F, Caillaud C. Inhibition of histamine release by nedocromil sodium reduces exercise-induced hypoxemia in master athletes. Med Sci Sports Exerc 1997;29:10-16.

9 Stewart IB, Labreche JM, McKenzie DC. Effect of a long- and short-acting beta2-agonist on exercise-induced arterial hypoxemia. Med Sci Sports Exerc 2003;35:603-607.

10 Wetter TJ, Xiang Z, Sonetti DA, et al. Role of lung inflammatory mediators as a cause of exercise-induced arterial hypoxemia in young athletes. $J$ Appl Physiol 2002;93:116-26.

11 Anderson SD, Holzer K. Pathophysiology of exercise-induced asthma. In Rundell KW, Wilber RL, Lemanske RF, eds. Exercise-induced asthma. Champaign, IL: Human Kinetics, 2002:69-100.

12 Coyle MA, Stager JM. Exercise-induced hypoxemia is ameliorated by nedocromil sodium and diphenhydramine hcl. Med Sci Sports Exerc 2001;33:S58.

13 Ferguson CS, Murphy JD, Brown KR, et al. Effect of nedocromil sodium on pulmonary gas exchange and vo2max. Med Sci Sports Exerc 2001;33:S58.

14 Wilkinson JR, Roberts JA, Bradding P, et al. Paradoxical bronchoconstriction in asthmatic patients after salmeterol by metered dose inhaler. BMJ 1992;305:931-2

\section{ELECTRONIC PAGES}

\section{Online case reports}

$\mathrm{T}$

he following electronic only articles are published in conjunction with this issue of BJSM

\section{Lateral plantar nerve injury following steroid injection for plantar fasciitis}

M D Snow, J Reading, R Dalal

A 41 year old man presented with pain and numbness affecting the lateral aspect of his foot after a steroid injection for plantar fasciitis. Examination confirmed numbness and motor impairment of the lateral plantar nerve. The findings were confirmed by electromyographic studies. The anatomy of the lateral plantar nerve and correct technique for injection to treat plantar fasciitis are discussed.

(Br J Sports Med 2005;39:e4l) http://bjsm.bmjjournals.com/ cgi/content/full/39/9/e4l

\section{Popliteus tendon tenosynovitis}

\section{S M Blake, N J Treble}

This case report highlights an unusual cause of anterolateral knee pain. The popliteus muscle arises from three originsthat is, the lateral femoral condyle, the fibula head, and the lateral meniscus-and inserts into the proximal tibia above the soleal line. It may be subjected to a number of pathologies including tenosynovitis, acute calcific tendonitis, rupture, and even avulsion. In this case, the diagnosis of popliteus tendon tenosynovitis was not made from magnetic resonance imaging findings, but was confirmed and successfully treated during arthroscopic examination.

(Br J Sports Med 2005;39:e42) http://bjsm.bmjjournals.com/ cgi/content/full/39/9/e42 